INTERNATIONAL JOURNAL OF MULTIdisciplinARY RESEARCh AND ANALysis

ISSN(print): 2643-9840, ISSN(online): 2643-9875

Volume 04 Issue 11 November 2021

DOI: 10.47191/ijmra/v4-i11-17, Impact Factor: 6.072

Page No.- 1597-1606

\title{
Influence of Promotion Strategy on Student Enrolment in Kenyan Universities
}

\author{
Dr. Kennedy Ntabo Otiso PhD ${ }^{1}$, Dr. Rael Mandago PhD ${ }^{2}$ \\ ${ }^{1}$ Senior Lecturer, School of Business, Department of Business Administration and Management Science, Koitaleel Samoei \\ University College, \\ (A constituent College of the University of Nairobi), P.O. Box 5-30307- Mosoriot, Kenya \\ ${ }^{2}$ Lecturer, School of Business, Department of Business Administration and Management Science, Koitaleel Samoei University \\ College, \\ (A constituent College of the University of Nairobi), P.O. Box 5-30307- Mosoriot, Kenya
}

\begin{abstract}
The purpose of this study was to focus on the influence of promotion strategy on student enrolment in Kenyan Universities. This study was guided by the Resource-Based View Theory. The study will adopt a descriptive cross-sectional study design. The target population for this study senior administrative staff, heads of departments/faculties and marketing managers at the universities. The researcher considered these groups for the population since they have accurate information on the performance of the universities. The target population comprised a total of senior personnel comprising of top administrative staff, heads of departments/faculties and marketing managers of the University. Stratified sampling was adopted for this study; there were four strata which include senior personnel in private universities. The researcher adopted structured questionnaires to collect data for the study. A pilot study was done to test the research instruments for validity and reliability. Before the collection of data, the researcher obtained a letter of authorization from the university as well as a permit from NACOSTI to undertake the study. Further, permission was sort from the management of the universities whose personnel participated in the study. Descriptive statistics was applied in the analysis of the quantitative data. Analysis of data was done and the findings presented using, charts, table and graphs. Additionally, a linear regression analysis was conducted to establish the relationship between the variables. From the findings, $46 \%$ of the respondents were marketing managers, $23 \%$ were heads of departments, $15 \%$ were senior lecturers while $16 \%$ were senior administrative officers. The findings imply that accurate data was obtained for the study since majority of the respondents had adequate knowledge on the strategy used by private universities. The findings revealed that the university charges fees based on the technicalities of programmes offered and that charges fees based on the demand for programmes offered. The findings also revealed that the university relies on social media advertising and internet uses outdoor advertising such as billboards, higher education exhibitions, print media such as newspapers, journals and magazines to promote their programmes in order to increase student enrolment. Finally, the findings revealed that the university offers unique programmes compared to other universities has a variety of programmes/courses for student to choose from and there are foundation programmes at the university for student who do not have minimum university entry requirements. It was concluded that the promotion strategy that were considered in the study if adopted effectively would result to increased levels of student enrolment in Kenyan private universities.
\end{abstract}

KEY WORDS: Promotion, strategy, enrolment

\section{BACKGROUND INFORMATION}

An important and interesting context is the higher education sector due to the fact that the sector is increasingly becoming market oriented with students increasingly becoming consumers globally (Chen, 2008).

The marketing concept in higher education was introduced by Krachenberg (1972) as a means of assessing the external environment and the higher education market. Krachenberg (1972) further urged institutions of higher learning to embrace marketing as a functional role. To grapple with the challenges, the leadership of the institutions of higher learning require 


\section{Influence of Promotion Strategy on Student Enrolment in Kenyan Universities}

marketing strategies that are effective as colleges and universities continue to adopt marketing as a strategy for increasing the enrolment of students.

The view of higher education institutions in developed economies such as the United Kingdom as profitable organizations shifted when leadership colleges and universities started considering academic programmes offered in the institutions as products and students as customers (Clagett, 2012). The term customer could however lead to the misunderstanding that degree programmes are products that are up for sale. However, scholars supporting this view argue that student or customer should paying for a service (academic programmes offered by a university) and the university to be providing quality academic programmes for the payment made by students (Durkin, McKenna, \& Cummins, 2012). Since universities and other institutions of higher learning are focused on the development of strong academic culture and not a service culture, most scholars are in disagreement with this perspective (Gibbs, 2011). In Germany, marketing mix strategies are now part of most The university dates back to 1996 when it started operating as a computer college under the name Thika Institute of Technology. It majorly offered computer training students with the objective of promoting the advancement of technological skills among students. In the year 2000, Thika Institute of Technology expanded and begun to offer management and information technology courses. In the same year, the institute was fledged as an institution of higher learning by the ministry of education science and technology (Mount Kenya University, 2017). In 2005, the Mount Kenya University started offering undergraduate and graduate courses in information technology, business management, arts as well as health and medical sciences in collaboration with The Jomo Kenyatta University of Agriculture and Technology (JKUAT) under a letter of interim issues by the ministry of higher education. In 2011, the institution was incorporated as a private university under the Private Universities Act 1989.

Since then, Mount Kenya University has emerged to be one of the most preferred by private universities by students seeking to enrol for higher education in the region with a student population that exceeds 13,000, a population that even some public universities have not been able to achieve. The university is ISO 9001:2008 certified and a member of the Inter-University Council for East Africa as well as the Association of Common Wealth Universities which are the main bodies that are mandated to ascertain the legality and quality of higher learning institutions to create trust among the general public. As Mount Kenya University aspires to increase its student population and offer quality education regionally and globally, it implements some marketing strategies aims at enhancing the knowledge of its capacity, achievements as well as the courses offered at the institutions.

\section{LITERATURE REVIEW}

A theoretical framework is comprised of the concepts and theories relevant to study variables. The theories discussed is the Resource-Based View Theory.

\section{Resource-Based View Theory}

The resource based view (RBV) conducts an analysis and interpretation of the resources that an organization has to understand how the resources are used by the organization to gain competitive advantage. The theory majors on the concept of complex-toimitate attribute of an organization as sources of competitive advantage and superior organizational performance (Braney, 1986). The resources that firms have include employees, assets, financial capital, technologies and organizational processes (Barney \& Wright, 2001). When it comes to marketing, resources usually comprise of channel bonding capabilities, customer equity, brand equity, pricing, product development, marketing communication, market information management capabilities among others. The difference between the provision of short term competitive advantage and that which can be sustained rests in the view that the resources are not perfectly mobile and heterogeneous in nature. According to the Resource based View, there is no mobility in resources, however, they are given consideration upon bundle, structure and leverage their valuable resources uniquely with an aim of maximizing their contribution to achieve sustainable advantage (Verhoef \& Leeflang, 2009). As argued by the Resource Based View, when the resources of a firm are non-sustainable and inimitable, then the sustainability of competitive advantage may be achieved (Barney 1991). This indicates the advantage of ensuring that the resources of a firm maintained, nurtured and renewed overtime. As asserted by Connelly, Ketchen and Slater (2010), the development of products that are friendly to the environment usually enable firms to achieve a sustainable competitive advantage. Based on the perspective of RBV, initiatives linked to sustainability residing at the intersection of social/environmental concerns and market opportunities have the highest likelihood of being successful.

\section{Promotion Strategies}

According to Kanoga (2016), promotion includes public relations, selling, advertising, sales promotions. If one particular institution of higher learning is focused on enrolling additional number of students than the existing institutions, the institution will have to apply corporate advertising strategies or undertaking promotional activities that leads to the creation of a liaison between the institutions of higher learning and the students. Publicity enhances media coverage for the institutions of higher 


\section{Influence of Promotion Strategy on Student Enrolment in Kenyan Universities}

learning as well as visibility that can improve the confidence as well as perceptions that prospective students and the general public might have. Buttle (1998) in their study of promotional strategies used in the higher education sector established that word of mouth (WOM) influences a variety of conditions which include: Expectations, awareness, attitudes perceptions, and behavioral intentions. As a result of these factors, positive word of mouth (WOM) affects the awareness of the private university and this awareness can turn the behavioral intentions of students. Buttle (1998) further established that educational exhibitions and fairs also enable private universities to showcase and promote their programmes to the prospective students. The study established that educational exhibitions and fairs are organized annually and most universities that intend to promote their programmes participate. It is also common for institutions of higher learning to routinely engage in the promotion and advertisement of particular universities by attending marketing or promotional events in various parts or a country or the world, and by having a strong online or internet presence.

In a study conducted by Ivy (2008) to examine the new marketing mix strategies used by South African University based on MBA students' attitudes and opinions towards the institutions' marketing initiatives, distinct underlying factors the instructions' marketing activities were established by the study. Some of the activities covered the traditional marketing. The study revealed that the marketing commutations used by the institutions were divided into two categories, the first category focused on direct mail promotion and the use of traditional media. It was further established in the study that areas of publicity and electronic media as well as press advertising were the main promotional strategies used by the institutions to market their programmes to prospective MBA students. Ngure (2018) research investigated the effects of marketing strategies and Strathmore's University performance. The study used a case study as research design or procedure. In addition, primary data was gathered from each dean of nine (9) schools through interviews and qualitative data analyzed through content analysis. The research results showed that the university had used promotion strategies that influenced sustainability that were press releases in new programmes launching, providing discounts to students pursuing ACCA and CPA with exemplary academic performance. Further, the university offers discounts to several groups of students such as early registrations were given 10 per cent discount, referral discounts, alumni enrolling for other courses were given 15 per cent discount and employees were given 20 per cent discount. Also, personnel are given commissions for undertaking specific professional courses, like managerial training and referring other people. Students were also given partial discounts or fully sponsored courtesy of partnerships with other corporate bodies.

Moogan (2011) examined whether marketing strategies used by private universities can improve the rate of student enrolment. The findings of the study established that private universities develop marketing and promotion strategies that are tailored towards strengthening the market position of a university, as such, a university is able to position itself in the market driven business environment hence an increase in the enrolment of students. Since academic programmes seemed to counter to the culture that focuses on traditional systems of the institutions of higher learning, they were not initially receptive of the market driven strategies since it seemed to run counter to the traditionally academic focused culture of universities (Gibbs, 2011). It was acknowledged by Gibbs (2011) that the consumerism approach of classifying prospective students as customer and university faculty as a service provider could lead to the emergence of potential ethical problems. The development of how a university as a brand is perceived by prospective students and the general public can be achieved through targeted communication and promotion activities as part of a university's public relations strategy. In a study by Bennett and Ali-Choudhury (2009) on the marketing and promotion strategies used by private universities to improve student enrolment, it was established that most private universities focus on social environment, student support networks, availability of job opportunities for graduates as well as the inclusion and diversity of the non-traditional student fraternity. Bennett and Ali-Choudhury (2009) identified that a university's logo do not has a significant impact on the promotion of a university and, that the mission and vision of a university play no significant role in the processes of decision-making in relation to enrolment by potential students. The scholars further noted that the identification of the type of strategies to be used for promotion effectively builds a university's brand hence enabling universities to maximize the budget that has been allocated for branding.

As the usage of social networking platforms continues to grow globally, the platforms are being widely used by universities as strategies student recruitment by developing university image, conducting measurements of conversion rates, and providing materials and resources to the general public as well as the internal community. However, some universities have been a little bit conservative when it come the use of social media platforms as a promotion strategy (Hayes, Ruschman, \& Walker, 2009). Hayes et al (2009) established in their study that social media is purposely avoided by some universities as part of promotion strategy. They also found out that marketing teams in other universities have been focusing mainly on tracking online reviews relating to their institutions and this enable the marketing teams to develop effective marketing and promotion strategies that that can increase the enrolment of potential students as well as react to potential issues that might be encountered while undertaking promotions. In study conducted by Pampaloni (2010) determine how prospective students react to promotion strategies initiated by universities, it was established that prospective students usually visit university websites and request online materials, the 


\section{Influence of Promotion Strategy on Student Enrolment in Kenyan Universities}

study also noted that prospective students are not likely to acknowledge receiving random e-mailed materials from the sales and marketing department of universities.

The findings of a study conducted by Clagett (2012) on the use of mails and brochures as a promotion strategy by universities established that that letters in the mail and brochures were highly preferred by college bound students. The study also established that the presence of universities on social media platforms varies greatly even though universities value online presence to enhance their promotion strategies. The study recommended that to attract prospective students effectively, the alignment of the three strategies that are aforementioned should be done. Additionally, social and cultural background of prospective students should be taken into account by universities and relate theme with university brand perception, organizational image as well as social media presence. This is because adopting any promotion strategy aimed at recruiting prospective students without a thorough understanding the social and cultural backgrounds of the students may limit the effectiveness of the promotion strategies in increasing student enrolment.

\section{RESEARCH METHODOLOGY \\ Research Design}

A descriptive research design was adopted for this study. It enabled the research to investigate the variables in the study without the necessity of manipulating and tampering with the findings. Additionally, the study was a systematic inquiry whereby the researcher was not able to directly influence on the variables (Mugenda \& Mugenda, 2012). The use of a descriptive research design study effectively enhanced the process of analyzing the data that was obtained during the study. Additionally, it significantly contributed to rigor of the study (Kumar, Talib, \& Ramayah, 2013).

\section{Target Population}

Population is a set of or subjects with common characteristics or attributes which are observable (Bhattacherjee, 2012). This study targeted senior administrative staff, heads of departments/faculties and marketing managers at Mount Kenya University main campus. The researcher considered these groups for the population since they have accurate information on Market mix strategies used by the university to increase student enrollment. The target population comprised a total of 149 senior personnel comprising of top administrative staff, heads of departments/faculties and marketing managers at Mount Kenya University.

Table 3.1. Target Population

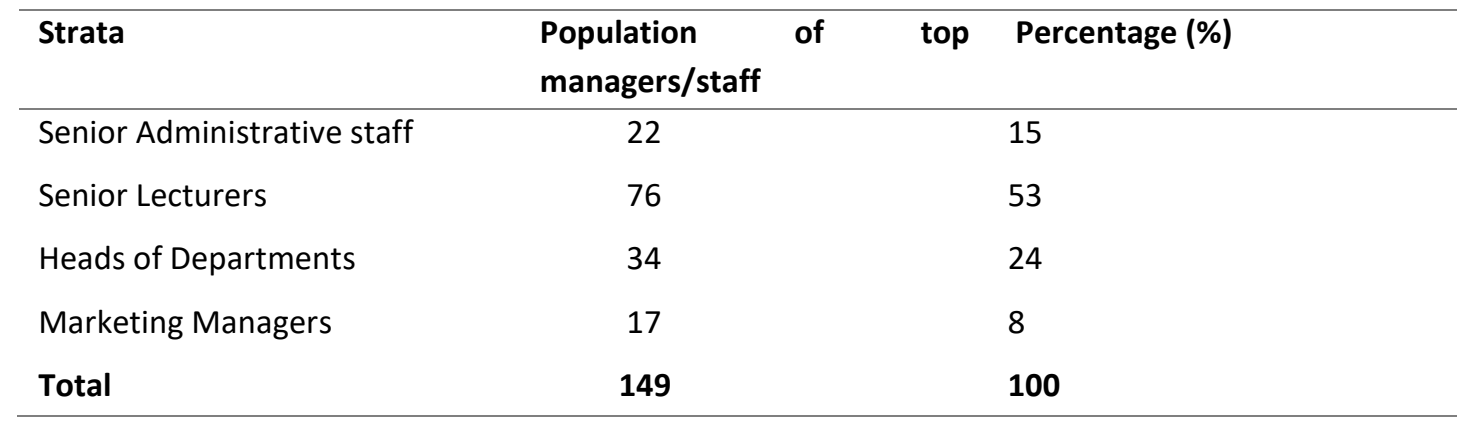

Source: Author (2021)

\section{Sample Design}

Sampling is the systematic procedure used for selecting participants of a research from a target population (Kombo and Tromp, 2006). Sampling is therefore important in research as it minimizes the challenges associated with consideration a whole population of research or using a portion of the population that is not representative (Easwaran and Singh, 2010). A sample size on the other hand is subset of the population targeted for a study that is used to represent the entire population of the study (Kumar, Talib, \& Ramayah, 2013). Stratified sampling was adopted for this study, there were four strata that included Senior Administrative staff, Senior Lecturers, Heads of Departments and Marketing Managers, 30\% of the population in each stratum was sampled for the study, according to Mugenda and Mugenda (2012), a minimum of $10 \%$ of a population is a representative sample in a research study and would suffice if the population units have similar characteristics. Thus, 44 respondents were sampled for the study. This is presented on table 3.1 below. 


\section{Influence of Promotion Strategy on Student Enrolment in Kenyan Universities}

Table 3.2. Sample Size

\begin{tabular}{|c|c|c|c|}
\hline Strata & $\begin{array}{l}\text { Population of top } \\
\text { managers/staff }\end{array}$ & Sample \% & Sample size \\
\hline Senior Administrative staff & 22 & 30 & 6 \\
\hline Senior Lecturers & 76 & 30 & 23 \\
\hline Heads of Departments & 34 & 30 & 10 \\
\hline Marketing Managers & 17 & 30 & 5 \\
\hline Total & 149 & & 44 \\
\hline
\end{tabular}

Source: Author (2021)

\section{Primary and Secondary Data}

The researcher adopted structured questionnaires to collect data for the study. Structured questionnaire has been preferred by the researcher since it makes the collection of data as well as coding of the raw data easy hence save time during research. The questionnaire captured each and every objective of the study as well the demographic characteristics of the study. A five Likert Scale was used for the statement that was provided for the respondents in the questionnaires. The study also used secondary data, secondary data related to the number of students enrolling for each programme the university annually. This data was obtained from the university's registry/register's office.

\section{Validity and Reliability of Data}

The researcher undertook a pilot study in two universities to pre-test the questionnaires. Validity is the degree to which a research instrument accurately assesses the specific concept that is being measured by the researcher (Bhattacherjee, 2012). For the purposes of determining the validity of the research instruments, the opinions of experts in this research field was obtained. For reliability, Internal Consistency Reliability was used, this measure of reliability was described using Cronbach's alpha, a Cronbach's alpha coefficient of 0.7 will be ideal.

\section{DATA ANALYSIS AND INTERPRETATION \\ Response Rate}

A total of 44 research questionnaires were distributed to the sampled respondents, all the respondents completely filled and return the questionnaires, this was $100 \%$ response rate.

\subsection{Background information}

\subsubsection{Age Distribution of the Respondents}

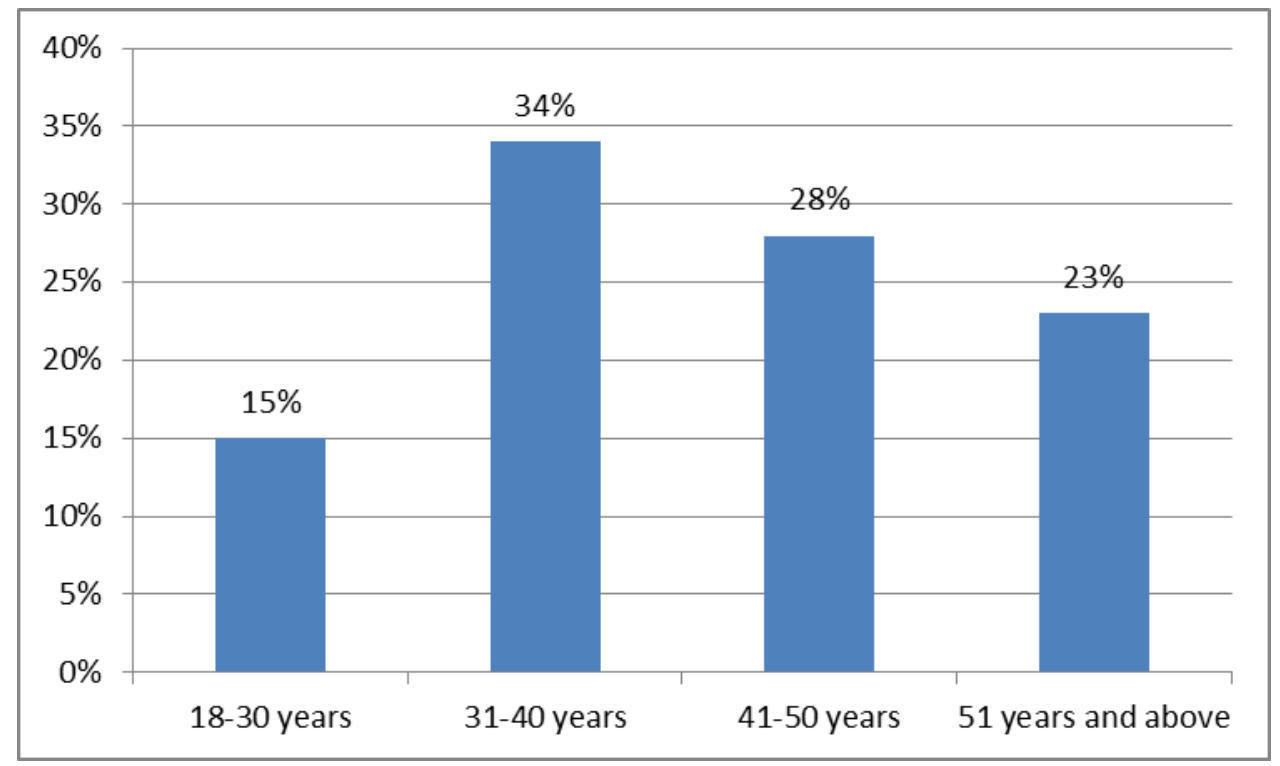

Figure 4.1: Age Distribution of the Respondents

Source: Author (2021) 


\section{Influence of Promotion Strategy on Student Enrolment in Kenyan Universities}

The study sought to establish the age distribution of the respondents, based on the data presented on figure 4.1 , a greater proportion of the respondents (34\%) were aged between 31 and 40 years, 28\% were aged between $41-50$ years, 15\% were aged between $18-30$ years while $23 \%$ were aged above 51 years.

\subsubsection{Gender Distribution of the Respondents}

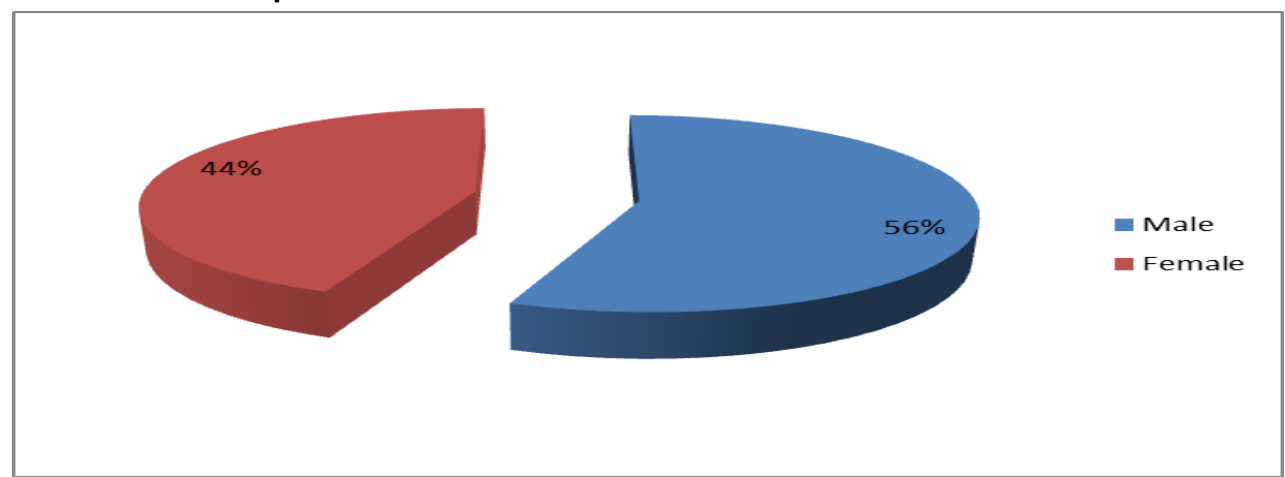

Figure 4.1.2: Gender Distribution of Respondents

Source: Author (2021)

Figure 4.2 presents the gender distribution of the respondents, based on the data, $56 \%$ were male while $44 \%$ were female.

\subsubsection{Respondents' Levels of Education}

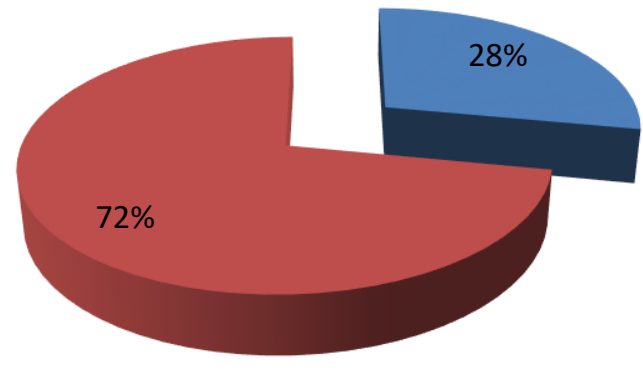

Bachelors Degree

Post Graduate Degree

\section{Figure 4.1.3: Respondents' Education Levels}

Source: Author (2021)

The study sought to establish the highest education levels attained by the respondents, based on the data presented on figure $4.3,72 \%$ of the respondents had post graduate degrees while $28 \%$ had bachelor's degrees. The findings imply that the researcher obtained accurate data from the respondents since a greater proportion were knowledgeable about marketing strategies used by universities.

\subsubsection{Respondents' Work Experience}

Table 4.1: Respondents' Work Experience

\begin{tabular}{lll}
\hline Duration & Frequency & $\%$ \\
\hline Less than 3 years & 4 & 6 \\
3-7 years & 10 & 23 \\
$8-11$ years & 18 & 43 \\
More than 11 years & 12 & 28 \\
\hline Total & $\mathbf{4 4}$ & 100 \\
\hline
\end{tabular}

Source: Author (2021) 


\section{Influence of Promotion Strategy on Student Enrolment in Kenyan Universities}

The study sought to establish the number of years the respondents had work at the university, based on the data, $43 \%$ had worked at the university for $8-11$ years, $28 \%$ had worked for more than 11 years, $23 \%$ had worked for 3-7 years while $6 \%$ had worked for less than 3 years. Based on the findings, the findings imply that the respondents gave relevant and accurate data on marketing mix strategies at the university since a greater proportion had worked at the university for more than 8 years.

\subsubsection{Respondents' Positions}

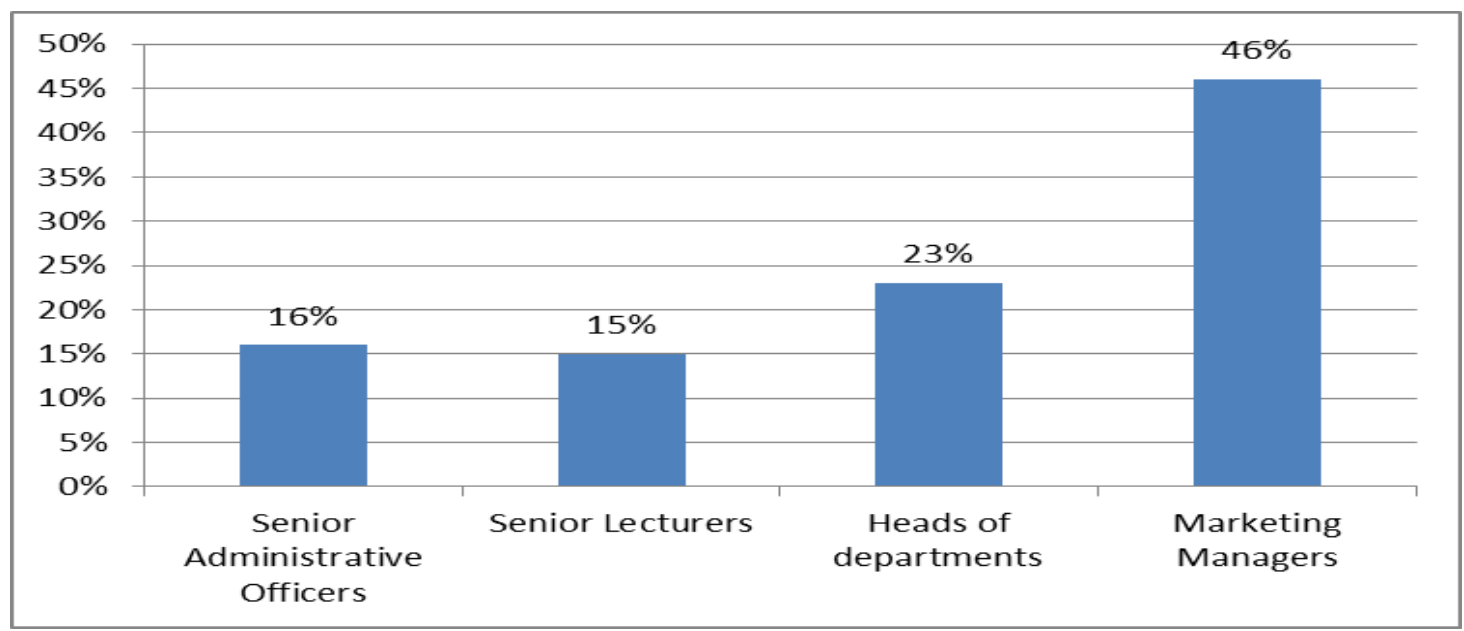

Figure 4.1.4: Respondents' Positions

Source: Author (2021)

The study sought to establish the positions held by the respondents at the university, based on the data presented on figure 4.4, $46 \%$ of the respondents were marketing managers, $23 \%$ were heads of departments, $15 \%$ were senior lecturers while $16 \%$ were senior administrative officers. The findings imply that accurate data was obtained for the study since majority of the respondents had adequate knowledge on the marketing strategies used by private universities.

Table 4.2. Promotion Strategies

\begin{tabular}{|c|c|c|c|c|}
\hline Promotion Strategy & Max & Min & Mean & $\begin{array}{l}\text { Std } \\
\text { Deviation }\end{array}$ \\
\hline The university uses the mainstream media for advertising & 2 & 4 & 4.06 & 1.169 \\
\hline The university relies on social media advertising and internet marketing & 3 & 4 & 4.78 & 0.846 \\
\hline $\begin{array}{l}\text { The university engages in corporate social responsibility within } \\
\text { communities }\end{array}$ & 2 & 4 & 3.42 & 0.803 \\
\hline $\begin{array}{l}\text { The university uses outdoor advertising such as billboards to attract } \\
\text { prospective students }\end{array}$ & 2 & 5 & 4.73 & 0.896 \\
\hline $\begin{array}{l}\text { The university participates in higher education exhibitions to show case its } \\
\text { programmes to prospective students }\end{array}$ & 4 & 5 & 4.85 & 0.871 \\
\hline $\begin{array}{l}\text { The university uses print media such as newspapers, journals and } \\
\text { magazines to advertise. }\end{array}$ & 4 & 5 & 4.77 & 1.051 \\
\hline
\end{tabular}

Source: Author (2021)

Table 4.4 presents data on Promotion Strategies, based on the findings, the respondents strongly agreed to the following statements: The university relies on social media advertising and internet marketing (Mean=4.78;SD=0.846); The university uses outdoor advertising such as billboards to attract prospective students (Mean=4.73;SD=0.896); The university participates in higher education exhibitions to show case its programmes to prospective students (Mean $=4.85 ; \mathrm{SD}=0.871$ ); and The university uses print media such as newspapers, journals and magazines to advertise (Mean=4.77; $\mathrm{SD}=1.051$ ). The respondents however neutral that: The university uses the mainstream media for advertising (Mean=3.06; SD=1.169) and that the university engages in corporate social responsibility within communities (Mean=3.42;SD=0.803). 


\section{Influence of Promotion Strategy on Student Enrolment in Kenyan Universities}

\section{Regression analysis}

Table 4.3: Model Summary

\begin{tabular}{lllll}
\hline Model & $\mathrm{R}$ & R Square & Adjusted R Square & Std. Error of the Estimate \\
\hline 1 & $.500^{\mathrm{a}}$ & .250 & .173 & .22147 \\
\hline
\end{tabular}

a. Predictors: (Constant), Price Strategies, Promotion Strategies, Place Strategies and Product Strategies.

Source: Author (2020)

Table 4.6 presents data on the model summery for the regression model. The adjusted $\mathrm{R}$ Square from the model summery is 0.250 which indicates that $25.0 \%$ of enrollment in private universities in Kenya can be explained by the independent variables.

\section{Analysis of Variance (ANOVA)}

The analysis of variance (ANOVA) indicates that the combined effect of the marketing strategies used by private universities significantly explained the enrollment of students in private universities. The results are presented in Table 4.7.

Table 4.4: ANOVA ${ }^{a}$

\begin{tabular}{lllllll}
\hline Model & & Sum of Squares & df & Mean Square & F & Sig. \\
\hline 1 & Regression & .637 & 4 & .159 & 3.245 & $.022^{\mathrm{b}}$ \\
& Residual & 1.913 & 39 & .049 & & \\
& Total & 2.550 & 43 & & &
\end{tabular}

a. Dependent Variable: enrollment in private universities

b. Predictors: (Constant), Promotion Strategies,

Source: Author (2021)

Data on Table 4.4 presents the statistics computed on the analysis of variance and shows a significance level of 0.022 which imply that the data ultimately draws conclusion based on the parameter of the population as the significance value ( $p$-value) is below $5 \%$, this imply that the model was statistically significant.

\section{Regression Coefficients}

A linear regression analysis was conducted with an aim of establishing the relationship between the marketing mix strategies used by universities and the enrollment of students in private universities. Coefficient of determination in the study describes the extent to which variations among the independent variables explain changes in the dependent variable (i.e the enrollment of students in private universities), that is explained by all the four predictor variables (i.e Price Strategies, Promotion Strategies, Place Strategies and Product Strategies).

Table 4.5: Regression Coefficients ${ }^{\mathrm{a}}$

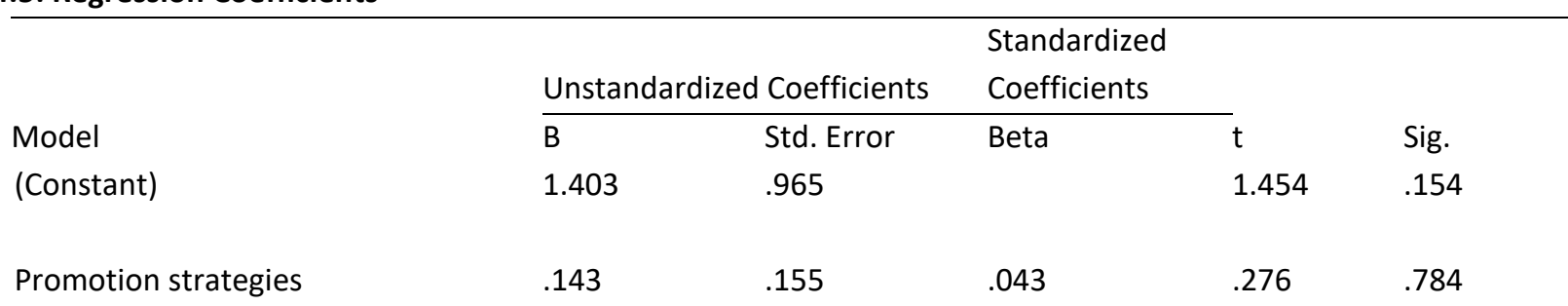

a. Dependent Variable: enrolment in private universities

Source: Author (2021)

Based on the regression coefficients presented on table 4.11, the overall equation model can be presented as follows:

$$
Y=\beta_{0}+\beta_{2} X_{2}+E
$$

From the above regression equation, it implies that when Promotion Strategies, zero, the enrollment of students in private universities would stand at 1.403 . A unit increase by 0.143 or $14.3 \%$. a unit increase in promotion strategies will lead to an increase 


\section{Influence of Promotion Strategy on Student Enrolment in Kenyan Universities}

in student enrollment in the private universities. From the regression coefficient table, it can be deduced that all the predictor variables were significant at $5 \%$ level of significance implying that the predictor variables have influence on the enrollment of students in private universities.

\section{SUMMARY OF FINDINGS CONCLUSIONS AND RECOMMENDATION}

\section{How do promotion strategies on student enrollment in private universities in Kenya?}

The findings established that $47 \%$ of the respondents believed that promotion strategies had a greater effect on the enrollment of students, on the other hand, $40 \%$ of the respondents believed it had great effects while $13 \%$ believed promotion strategies have the least effects on student enrolment in private universities. The findings further revealed that the university relies on social media advertising and internet uses outdoor advertising such as billboards, higher education exhibitions, print media such as newspapers, journals and magazines to promote their programmes in order to increase student enrollment. Other studies have also established that the use of social media and other technology driven advertisement enhances student enrolment.

\section{Conclusion}

The study revealed that the level of adoption of the specific marketing mix strategies was significantly determined the level of student enrolment in private universities. It can therefore, be concluded that the adoption of marketing mix strategies by private universities significantly improves the levels of student enrolment in Kenyan private universities. Any form of promotion strategy that a university engages in will significantly influence the enrollment of students. Most private universities usually engage in broadcast media, print media as well as digital media advertising to promote their programmes.

\section{Recommendations}

Kenyan private Universities need to make provisions for promotion (advertisement) and continued improvement and development of physical facilities in their annual budget. The universities must also have clear timelines for the implementation of their marketing mix strategies in order to succeed in their objective of increasing student enrollment and general institutional effectiveness.

\section{Suggested Areas for Future Research}

A related study should be conducted in other private institutions of higher learning such as Technical and Vocational Training Institutes determine whether the same conclusions can hold. A survey should be done for middle level colleges in Kenya because generalizing results of a case study is limited, a survey will act as a better pointer to the adoption of marketing mix strategies to increase student enrollment as well as the challenges of adopting the strategies thereby enabling generalization of the results of such a study.

\section{REFERENCES}

1) Ansoff, I. (1957). Corporate Strategy. New York: McGraw-Hill. .

2) Barney, J., \& Wright, M. D. (2001). The resource-based view of the firm: ten years after 1991. Journal of Management, 27(6), 625-641.

3) Bryman, A., \& Bell, E. (2011). Business Research Methods . (3rd. ed.). Oxford, UK: Oxford University Press.

4) Chang, R., Zuo, J., Zhao, Z., Zillante, G., Gan, X., \& Soebartoa, V. (2017). Evolving theories of sustainability and firms: History, future directions and implications for renewable energy research . Renewable and Sustainable Energy Reviews, 48-56.

5) Connelly, B. L., Ketchen, D. J., \& Slater, S. (2010). Toward a "theoretical toolbox" for sustainability research in marketing. Journal of the Academy of Marketing Science , 39(1), 86-100 DOI 10.1007/s11747-010-0199-0.

6) Dalati, S., \& Al Hamwi, S. E. (2016). Sustainable Development In Higher Education Through Service Quality And Price Fairness: Empirical Evidence From Private Universities In Damascus, Syria. Entrepreneurship and Sustainability Issues, 4(1): 25-38. DOI: http://dx.doi.org/10.9770/jesi.2016.4.1(3) .

7) Ivy, J. (2008). A new higher education marketing mix: the 7Ps for MBA marketing. International Journal of Educational Management, 22(4), 288-299.

8) Kanoga, S. G. (2016). Influence Of Marketing Mix Dimensions On Perfomance Of Shopping Malls In Nairobi City County Kenya., Masters Thesis, Kenyatta University.

9) Kombo, D. K., \& Tromp, D. L. (2006). Proposal and Thesis Writing, An Introduction. Nairobi, Kenya: Paulines Publication.

10) Kumar, M., Talib, S. A., \& Ramayah, T. (2013). Business Research Methods. Kuala Lumpur: Oxford University Press .

11) Mugenda, A. G., \& Mugenda, O. M. (2012). Research methods dictionary. 


\section{Influence of Promotion Strategy on Student Enrolment in Kenyan Universities}

12) Ngure, J. (2018). Influence of Marketing Strategies on Performance of Strathmore University, Kenya, Master Thesis, Strathmore University.

13) Salvioni, D. M., Franzoni, S., \& Cassano, R. (2017). Sustainability in the Higher Education System: An Opportunity to Improve Quality and Image. Sustainability, 9(914), 1-27.doi:10.3390/su9060914.

14) Starck, K., \& Zadeh, S. H. (2013). Marketing within higher education institutions - A case study of two private Thai universities . Mälardalen University, Västerås, Sweden .

15) Verhoef, P. C., \& Leeflang, P. S. (2009). Understanding the marketing department's influence within the firm. Journal of Marketing, 73(2), 14-37. 